\title{
IMPLICAÇÕES DA OPÇÃO METODOLÓGICA PELO MATERIALISMO HISTÓRICO-DIALÉTICO NA PRODUÇÃO ACADÊMICA DO Centro-Oeste/BrasiL ${ }^{*}$
}

\author{
Ruth Catarina C. R. de Souza; \\ Solange Martins Oliveira Magalhães, \\ da Universidade Federal de Goiás.
}

\begin{abstract}
RESUMO: Este artigo apresenta os resultados da análise da produção acadêmica sobre professores, período 2006-2007, dos programas de pós-graduação em educação do Centro-Oeste. Pautada no materialismo histórico dialético (MHD), essa foi desenvolvida pela REDECENTRO - Rede de Pesquisadores sobre Professores(as) no Centro-Oeste/Brasil. O presente trabalho tem como objetivo analisar, nessa produção, a que é desenvolvida pautada na opção do MHD como método, bem como suas relações com a abordagem qualitativa, os objetivos e as conclusões construídas. Identifica-se falta de clareza entre o significado de método e abordagem do trabalho e, também, dispersão teórica e metodológica. Quanto aos objetivos relacionados ao MHD, destaca-se a necessidade de os mesmos não serem mero cumprimento de uma formalidade, mas definidos como objetivos de tipo compreensivo, relacionados aos mesmos pressupostos epistemológicos, ontológicos, gnosiológicos, e recuperados nas conclusões dos estudos.

Palavras-chave: Pesquisa Educacional. Formação de professores. Método.
\end{abstract}

A questão do rigor e da relevância da produção educacional tem provocado debates, confrontos e diálogos nos últimos anos. Isso se liga às notáveis transformações pelas quais passou o campo nas últimas décadas,

\footnotetext{
* Artigo recebido em 24/4/2012 e aprovado em 14/08/2012.
} 
principalmente a partir do século $\mathrm{XX}$, momento em que se amplia a preocupação científica com as demandas da área da educação.

Em um resgate histórico, tem-se que no fim da década de 1930, no Brasil, houve a criação do Instituto Nacional de Pesquisas Educacionais (INEP), importante marco no processo de institucionalização de uma política científica. O INEP foi precursor de estudos sistemáticos da área educacional, tendo impulsionado, também, a criação do Centro Brasileiro de Pesquisas Educacionais (CBPE) e os Centros Regionais do Rio Grande do Sul, São Paulo, Bahia e Minas Gerais. Esses se tornaram espaços destinados à formação de pesquisadores e ao desenvolvimento da pesquisa científica.

Outro fator que demarcou a institucionalização da política científica no Brasil foi à criação do Conselho Nacional de Pesquisas (CNPq) e da Companhia de Aperfeiçoamento de Pessoal de Ensino Superior (CAPES) na década de 1950. Nesse período, até o início da década de 1960, as medidas referentes às pesquisas científicas visavam à formação de pesquisadores treinados para as necessidades do setor produtivo. A CAPES, ${ }^{2}$ por exemplo, desde sua origem, se destinou à formação de pessoal, pesquisadores de alto nível em todas as áreas do conhecimento, ficando responsável, a partir da década de 1970, por elaborar, coordenar e implementar os Planos Nacionais de Pós-Graduação (PNPGs). Esses documentos, além de trazerem os diagnósticos da pós-graduação, sintetizam as diretrizes que norteiam as políticas públicas de qualificação de pessoal em nível de mestrado e doutorado. A CAPES os editou (os PNPGs) a cada seis anos, até o V PNPG (2005-2010), sempre voltados para determinadas iniciativas que catalisassem e dinamizassem tanto a atuação do órgão, como a destinação de recursos. Contudo, a partir do VI PNPG, a projeção de metas passou a ser mais em longo prazo (2011-2020), sendo as prioridades, entre outras: melhorar a organicidade com as Fundações Estaduais (FAPs); radicalizar na indução do mestrado profissionalizante; qualificar e melhorar a atuação da CAPES voltada à Educação Básica (BIANCHETTI, 2011). Já o CNPq destinava-se (como ainda se destina) à capacitação e formação de pesquisadores nas várias áreas científicas.

A política científica brasileira teve seu avanço a partir da década de 1960, com os órgãos mencionados e com a implementação dos programas de pós-graduação - mestrados e doutorados - em que se passou a desenvolver atividades de pesquisa. Vale salientar que no Brasil, em função de sua história sociopolítica, especialmente durante a década de 1960, houve a predominância de uma conjuntura de política desenvolvimentista que não deixou de influenciar os objetivos da pesquisa educacional. Seguindo uma linha histórica, no final da década de 1970 e começo dos anos de 1980, ocorreu 
um grande desenvolvimento de programas de pós-graduação em educação e com eles consolidaram-se grupos de pesquisa; mas, paralelamente, ampliaram-se também os desafios teóricos conceituais que se agravaram nas três últimas décadas.

Do final da década de 1960 até os dias de hoje, os cursos de pósgraduação cresceram e se expandiram, constituindo o que é hoje conhecido como o sistema nacional de pós-graduação. Em linhas gerais, aos poucos se multiplicaram os centros de pesquisa acadêmica; com eles expandiramse e modificaram-se as temáticas dominantes, assim como as orientações teórico-metodológicas.

Do ponto de vista metodológico, o período também foi de crescimento de "alguns problemas de base na construção das próprias pesquisas" (GATTI, 2001, p.68), o que precipitou, em meados da década de 1990, a necessidade de se investir na solidez das bases epistemológicas que ajudassem os pesquisadores na composição de suas pesquisas.

De modo mais localizado, nos programas de pós-graduação do Centro-Oeste, conforme Magalhães e Souza (2012), os problemas basilares na realização das pesquisas estão relacionados, sobretudo, às questões de teoria e de método. As dificuldades centram-se na construção de categorias teóricas consistentes, conforme também especificaram Kuenzer e Moraes em pesquisa realizada em 2005.

Magalhães e Souza (2012) ainda advertem que a dispersão teórica e metodológica (presente na produção acadêmica analisada) tem conduzido a pesquisa a um sincretismo teórico, fazendo com que se perca a compreensão sócio-histórica e, portanto, sua vocação de emancipação e transformação social, o que compromete, primeiro, o rigor e, segundo, a relevância das pesquisas.

Por certo, essas questões configuram um desafio; o levantamento do estado do conhecimento sobre o assunto tem dado visibilidade às tensões e problemas específicos das pesquisas da área e, também, apontado os rumos de sua melhoria (GOUVEIA, 1971, 1976; CUNHA, 1979; MELLO, 1982; 1983; 1985; GATTI, 1983, 1992, 2001, 2002; ANDRÉ, 2007, 2011; MAGALHÃES; SOUZA, 2012).

Historicamente e na temporalidade acima referida, constrói-se um movimento meta-analítico de análise e crítica das pesquisas educacionais. Esse pode ser evidenciado, particularmente, na proposta da REDECENTRO, uma rede de pesquisadores que tem buscado compreender os múltiplos aspectos que envolvem a temática professores nas pesquisas acadêmicas da região Centro-Oeste. 


\section{A CONSTRUÇÃO TEÓRICO-METOdOLÓGICA DA PESQUISA EM REDE}

Para contextualizar o trabalho da REDECENTRO, é necessário entender que a mesma surgiu a partir da pesquisa $A$ produção acadêmica sobre professores: pesquisa interinstitucional da Região Centro-Oeste que vem sendo desenvolvida há oito anos, envolvendo oito instituições: Universidade de Brasília (UnB), Universidade Federal de Goiás (UFG), Universidade Federal de Mato Grosso (UFMT), Universidade Federal de Mato Grosso do Sul (UFMS), Universidade Federal de Uberlândia (UFU), Universidade de Uberaba (UNIUBE); Universidade Federal do Tocantins (UFT) e Universidade Estadual de Goiás (UEG); também se associou, recentemente, ao Observatório Internacional da Profissão Docente - OBIPD, da Universidade de Barcelona, com a proposta de analisar a produção acadêmica sobre o tema "professores", em âmbito local, nacional e internacional.

De caráter cooperativo, a Rede agrega pesquisadores atuantes em várias disciplinas no contexto acadêmico, desenvolve processo de trabalho de natureza interinstitucional e interdisciplinar, e tem criado condições para a elaboração de uma síntese dos conhecimentos produzidos. Contribuindo para o enriquecimento da pesquisa na área, as oito equipes brasileiras têm desenvolvido um projeto que analisa as produções acadêmicas em cada um dos programas de pós-graduação em educação envolvidos. Isso tem possibilitado avanços à produção, a partir da realidade regional do CentroOeste brasileiro, em suas articulações nacionais e internacionais.

A partir do ano de 2010, a Rede foi oficializada, tendo como núcleo coordenador a Universidade Federal de Goiás. As instituições envolvidas aderiram por meio de um Termo de Convênio e Regimento Interno, assinado por seus reitores. Esse ato selou o compromisso institucional, bem como definiu o coordenador de cada núcleo local e sua equipe.

Privilegiando o estudo da temática "professores", a REDECENTRO tem o objetivo de trabalhar as diversas arquiteturas da produção acadêmica, para compreendê-la e buscar indicadores qualitativos que contribuam com a abertura de perspectivas que incentivem posições de análise adequadas sobre o tema, aspecto que inclui elevar a formação teórica e epistemológica dos que se dedicam ao estudo, à pesquisa e aos processos de orientação.

A Rede tem se articulado através de seminários, grupos de estudos, reuniões técnicas, contatos online, palestras presenciais e virtuais, participação em orientações coletivas e em bancas de pós-graduação, movimento que tem fortalecido uma relação dialética e dialógica entre os participantes. Percebese o crescimento mútuo, privilegiando a formação de pesquisadores, alunos 
de pós-graduação, alunos de iniciação científica, pesquisadores-formadores, e orientadores para as pesquisas educacionais.

Essa proposta justifica-se a partir da consolidação do trabalho cooperativo de oito anos que se desenvolve nessa pesquisa meta-analítica. Esta se caracteriza como um tipo de pesquisa avaliativa, cuja relevância principal é influenciar programas de pós-graduação, porque explicita os problemas aos interessados (docentes, estudantes, pesquisadores, universidades, agências de fomento), para que possam apreciar criticamente o conhecimento produzido. Ainda é preciso destacar que tem ajudado a melhorar processos de orientação e condução das pesquisas, tanto em termos de produtos como de procedimentos.

Para esclarecer o percurso metodológico desenvolvido pela Rede, elege-se a perspectiva crítica como caminho na busca de seus objetivos. No que versa sobre o rigor e a relevância do trabalho desenvolvido, a REDECENTRO tem mantido um trabalho sistemático que envolve identificar, catalogar, ler na íntegra os trabalhos, destacando as seguintes categorias de análise: temas desenvolvidos, tipo de pesquisa, ideário pedagógico, problemas, objetivos, referenciais teóricos utilizados, conclusões, resultados, e a questão do método. Essas categorias compõem o instrumento de análise construído pelo grupo, denominado como ficha de análise. Esse instrumento é utilizado por todos os pesquisadores ligados à Rede.

Observe o processo de construção e utilização do instrumento - ficha de análise - com a questão referente ao método, conforme exemplificado na Tabela 1

Tabela 1 - Questão referente ao método/Produção acadêmica sobre professores(as).

\begin{tabular}{|l|l|l|l|}
\hline QUESTÃO SOBRE O MÉTODO & SIM & NÃO & OBS. \\
\hline 1. Está claramente explicitado & & & \\
\hline 2. Não está claramente explicitado, mas pode ser identificado. & & & \\
\hline 3. Não pode ser identificado. & & & \\
\hline
\end{tabular}

Fonte: REDECENTRO - Rede de Pesquisadores sobre professores(as) no Centro-Oeste/Brasil.

Como se disse acima, atualmente a ficha é composta por uma série de categorias e seus descritores. Inicialmente, era menos complexa no que se refere ao método, conforme apresentado na Tabela 1 . $O$ instrumento de análise, perguntava se o método estava ou não claramente explicitado no trabalho e, caso não estivesse, se poderia ser identificado. $O$ método só era julgado como não identificado se, além de não ter sido declarado, o leitor da 
dissertação (pesquisador) não conseguisse encontrar alguma característica que ligasse o estudo a qualquer abordagem metódica, conforme nosso instrumento. Para esses trabalhos era solicitado o parecer de um segundo leitor. Para que o método fosse considerado como não identificado, os pareceres deveriam coincidir, além de, às vezes, desencadear intensos debates entre os membros das equipes, em relação às características identificadas.

Ao término da primeira fase da pesquisa, identificou-se um número elevado de trabalhos em que os leitores não identificaram o método. O grupo questionou se isso era devido a uma fragilidade metodológica dos autores dos trabalhos, dos seus orientadores, ou dos referenciais metodológicos dessas pesquisas; ou, ainda, se seriam o reflexo de limitações dos pesquisadores (nossas próprias) e formadores de pesquisadores. Essas foram as inquietações que promoveram uma nova fase da pesquisa.

A partir desses questionamentos, o grupo sentiu a necessidade de aprofundar seus estudos e de construir um novo instrumento de análise, aspecto que promoveu debates ao longo de vários encontros, mas que, ao final, possibilitou a construção da ficha de aprofundamento 1. Nesse novo instrumento, buscou-se evidenciar tipos de métodos, cujos descritores explicitavam suas bases epistemológicas, o que envolvia reconhecer serem possíveis diferentes compreensões da relação sujeito/objeto, inclusive diferentes maneiras de se abordar e compreender o processo de construção do conhecimento.

Essa sistemática de reflexão, principalmente no que se refere ao método e sua influência na investigação dos objetos de estudo, possibilitou o entendimento de três perspectivas epistemológicas - a dialética, a fenomenológica e a positivista - como as mais recorrentes no campo da pesquisa educacional. Foram essas que passaram a compor o segundo instrumento de análise. Ainda é preciso destacar que, na categoria método, sua descrição pautou-se nos estudos de autores que se ligam à perspectiva crítica (LIMOEIRO, 1976, 1978; LUNA, 1988; BICUDO, 1994; BELLO,

Dando continuidade à história da construção teórico-metodológica da Rede, registra-se que, após um longo período de estudos e discussões, o grupo optou por estabelecer indicadores de análise que traduzissem cada um dos tipos de métodos. Estabelecer esses indicadores significou explicitar o entendimento que o grupo construiu de cada uma das perspectivas metódicas, seus paradigmas científicos, concepções de mundo, sociedade, sujeito e educação. Essas categorias de análise e seus indicadores foram apreciados por especialistas em cada uma das abordagens, no sentido de validação rigorosa do instrumento, cuja elaboração significou também 
o estabelecimento de um parâmetro comum por meio do qual seriam analisadas as dissertações e teses, objeto dessa ampla pesquisa conduzida pela Rede.

No caso do materialismo histórico dialético (MHD), foram definidos os seguintes indicadores de análise: a) abordar o objeto na perspectiva histórica, a partir de suas origens; b) buscar, na história, as origens do problema, do todo e não de tudo; c) trabalhar com os sujeitos típicos a serem pesquisados; d) apresentar o concreto pensado, evidenciando o objeto que estava oculto, o movimento dialético; e) utilizar categorias marxistas para análise: trabalho, alienação, ideologia, classe social, contradição, negação, totalidade, universalidade; f) articular teoria e prática e denominá-la práxis; g) apresentar os dados, confrontando seus nexos internos e contraditórios com a totalidade; $h$ ) ratificar o referencial teórico utilizado.

A história da pesquisa passou por duas fases que se complementam e representam o avanço teórico-metodológico do grupo. Na primeira fase, foram realizadas a leitura, análise e sistematização de 360 dissertações produzidas nos programas estudados sobre o tema professores, no período de 1999-2005. ${ }^{3}$

Com o intuito de aprofundar a questão do método, bem como dos outros indicadores de análise, a segunda fase da pesquisa abarcou um total de $20 \%$ dos trabalhos de cada instituição da Rede, totalizando 66 trabalhos, ${ }^{4}$ selecionados tendo em vista os seguintes critérios: pertencerem a diferentes linhas de pesquisas, terem sido orientados por diferentes professores e defendidos em anos diferentes (SOUZA e MAGALHÃES, 2011).

Nesse momento, identificaram-se vários problemas na produção acadêmica do Centro-Oeste/Brasil, relacionados à utilização adequada do método, e compreendeu-se que havia muito a melhorar, tanto no rigor quanto na relevância dos estudos, entendendo que isso comprometia as pesquisas na área educacional.

A partir do diálogo interno e aprofundamento dos estudos, decidiuse que era necessário dar um passo além, aprofundar ainda mais as análises e interpretações. Esse processo de aperfeiçoamento dos estudos permitiu desencadear, então, a terceira fase da pesquisa que se caracterizou pela evolução do entendimento construído e acarretou dar ênfase ao método como eixo norteador da crítica do conhecimento que a própria Rede produzia. Assim pensando, o grupo reviu novamente o instrumento de análise, reformulando-o de forma a explicitar novos indicadores, mas, agora, em uma nova dimensão, já que passaram a ser articulados a cada tipo de método. Como a base epistemológica do estudo é a materialista histórico-dialética, 
percebeu-se que esse foi um movimento adequado, pois exigiu repensar os princípios que retroalimentavam a metodologia desenvolvida pela Rede.

Para exemplificar a mudança no instrumento, a ficha de aprofundamento da fase anterior apresentava as concepções de educação/professor - tradicional, escolanovista, tecnicista, crítico-reprodutivista, racionalidade técnica, crítica e pós-crítica - com seus indicadores, conforme exemplo abaixo.

Quadro 1 - Trecho do instrumento de análise sobre as concepções de educação.

\begin{tabular}{|c|c|c|}
\hline \multirow[t]{2}{*}{ CATEGORIAS } & Posicionamento do autor: & OBS \\
\hline & $\begin{array}{l}\text { ( ) está claramente explicitada. Qual? } \\
\text { ( ) não está claramente explicitada, mas pode ser identificada: } \\
\text { ( ) não pode ser identificado } \\
\text { ( ) outra resposta }\end{array}$ & \\
\hline \multirow[t]{7}{*}{$\begin{array}{l}\text { EDUCAÇÃO } \\
\text { TRADICIONAL }\end{array}$} & INDICADORES & OBS \\
\hline & $\begin{array}{l}\text { 1. A memória é entendida como base da inteligência e a aprendizagem é } \\
\text { alicerçada na repetição. ( ) }\end{array}$ & \\
\hline & $\begin{array}{l}\text { 2. O poder dos valores e conhecimentos hegemônicos sobrepõe-se aos } \\
\text { conflitos. ( ) }\end{array}$ & \\
\hline & 3. Os modelos e conteúdos pautam-se em idealizações. ( ) & \\
\hline & $\begin{array}{l}\text { 4. Os métodos primam pelo verbalismo e pelo pensamento lógico formal. } \\
\text { ( ) }\end{array}$ & \\
\hline & $\begin{array}{l}\text { Referencial referente a concepção de educação utilizada. } \\
\text { Autores propostos pela ficha: Dürkheim, Herbart, Comênios. }\end{array}$ & \\
\hline & Outros autores: & \\
\hline \multirow[t]{7}{*}{$\begin{array}{l}\text { EDUCAÇÃO } \\
\text { ESCOLANOVISTA }\end{array}$} & INDICADORES & OBS \\
\hline & 1. A inteligência é instrumento de resolução de problemas. ( ) & \\
\hline & 2. Os processos ativos são privilegiados para o aluno aprender fazendo. ( ) & \\
\hline & 3. A dimensão psicológica é enfatizada no processo de aprendizagem. ( ) & \\
\hline & 4. O foco do conhecimento escolar pauta-se no método científico. ( ) & \\
\hline & $\begin{array}{l}\text { Referencial referente a concepção de educação utilizada: } \\
\text { Autores propostos pela ficha: Dewey, Rousseau, Pestalozzi, Anísio } \\
\text { Teixeira, Lourenço Filho, Montessori. }\end{array}$ & \\
\hline & Outros autores: & \\
\hline
\end{tabular}

Fonte: REDECENTRO - Rede de Pesquisadores sobre professores(as) no Centro-Oeste/Brasil.

Tendo como base de definição o método, as concepções foram redesenhadas, realizando-se importantes modificações. Seguindo o mesmo exemplo dado acima, os indicadores das concepções de educação e professor 
foram reestruturados de maneira que, agora, o ideário pedagógico está pautado de acordo com cada corrente metódica.

Nessa lógica processual, especificou-se não apenas a concepção de educação, mas também a de escola, professor e processo ensinoaprendizagem como constituidores do ideário pedagógico, conforme cada método definido pelo grupo: MHD, fenomenológico, e positivista.

No exemplo abaixo, apresentam-se os novos indicadores de análise, no caso específico do MHD:

Quadro 2 - Trecho do instrumento de análise sobre o ideário pedagógico conforme MHD

\begin{tabular}{|c|c|c|}
\hline \multirow{2}{*}{$\begin{array}{l}\text { CATEGORIA } \\
\text { IDEÁRIO PEDAGÓGICO }\end{array}$} & Posicionamento do autor: & OBS. \\
\hline & $\begin{array}{l}\text { ( ) está claramente explicitado. Qual? } \\
\text { ( ) não está claramente explicitado, mas pode ser identificado: } \\
\text { ( ) não pode ser identificado } \\
\text { ( ) outra resposta }\end{array}$ & \\
\hline \multirow{7}{*}{$\begin{array}{l}\text { PERSPECTIVA } \\
\text { MATERIALISTA-HISTÓRICO } \\
\text { DIALÉTICA }\end{array}$} & INDICADORES & OBS. \\
\hline & $\begin{array}{l}\text { A educação é compreendida como processo humanizador de } \\
\text { caráter técnico, político e social. Implica o caráter relacional } \\
\text { em que os sujeitos apropriam-se das práticas culturais } \\
\text { historicamente construídas, transformam o mundo e a si } \\
\text { mesmos. Decorre de uma relação dialética entre a produção } \\
\text { e a transmissão de conhecimentos assumindo um potencial } \\
\text { transformador da sociedade. ( ) }\end{array}$ & \\
\hline & $\begin{array}{l}\text { A escola é parte inseparável da totalidade social, e como } \\
\text { tal, apresenta as mesmas situações de reprodução e de } \\
\text { mudança que caracterizam aquela totalidade. Representa uma } \\
\text { possibilidade de ruptura e transformação da sociedade ao } \\
\text { proporcionar a construção do conhecimento emancipador. ( ) }\end{array}$ & \\
\hline & $\begin{array}{l}\text { O professor é sujeito historicamente situado, marcado pelas } \\
\text { relações políticas, econômicas e culturais, produto e produtor } \\
\text { da realidade social. O professor é mediador, intelectual } \\
\text { defensor de uma atitude de resistência, uma ação que provoca } \\
\text { engajamento e participação no processo de mudança social. } \\
\text { Oportuniza construções diversas, de maneira crítica, aberta e } \\
\text { autônoma, o que demanda a elaboração reflexiva e saberes } \\
\text { emancipatórios. ( ) }\end{array}$ & \\
\hline & $\begin{array}{l}\text { O processo de ensino-aprendizagem se expressa numa práxis } \\
\text { que propicia construções de conhecimentos e de sujeitos } \\
\text { críticos, abertos, autônomos e emancipados. O diálogo, a } \\
\text { reflexão, a contradição e o conflito são elementos essenciais } \\
\text { para implicar os sujeitos em uma relação de aprendizagem } \\
\text { na qual a internalização e construção de conhecimentos } \\
\text { possibilita a transformação das relações e da sociedade. ( ) }\end{array}$ & \\
\hline & $\begin{array}{l}\text { Referencial utilizado/Autores propostos pela ficha: Marx; } \\
\text { Gramsci; Adorno; Marcuse; Mészáros; Vygotsky; Leontiev; Luria; } \\
\text { Wallon; Freire. }\end{array}$ & \\
\hline & $\begin{array}{l}\text { Outros autores: Saviani; Frigotto; González Rey; Angel Pino; } \\
\text { Luis Carlos de Freitas; Newton Duarte; Maria Tereza Assunção } \\
\text { de Freitas; Libâneo e outros. }\end{array}$ & \\
\hline
\end{tabular}

Fonte: REDECENTRO - Rede de Pesquisadores sobre professores(as) no Centro-Oeste/Brasil. 
Ainda foram incluídas, na fich a de aprofundamento 2, novas categorias de análise como: o problema, os objetivos (principal e específicos), as questões levantadas pelos estudos, a abordagem do trabalho, os resultados e a conclusão. Buscava-se saber se o autor articulava os dados aos fundamentos teóricos; se se apoiava em referenciais adequados para apresentar/discutir seus resultados; e, por último, se havia articulação entre a problematização, os objetivos e as conclusões apresentadas nas considerações finais.

Com as mudanças acordadas sobre essa reestruturação, buscou-se construir resultados mais articulados e guiados pelas diretrizes do método assumido (MHD), condição sine qua non para se avançar na construção e na consolidação de novas formas de produzir conhecimento.

\section{ArticulaÇões teÓRICO-METOdolóGICAS NA PRODUÇÃo ACADÊMICA Do CENTRO- OESTE/BRASIL: ALGUNS RESULTADOS SOBRE MÉTODO, ABORDAGEM DO ESTUDO E OBJETIVOS}

$\mathrm{Na}$ atual fase da pesquisa, foram selecionados e analisados 132 trabalhos relativos à produção 2006-2007. Desse total, 75 (ou 55\%) adotaram o materialismo histórico dialético (MHD) como método de pesquisa; desses 75 , foi declarado que em $95 \%$ a abordagem assumida era a qualitativa. Ressaltase que a pesquisa qualitativa também foi desenvolvida a partir de outros paradigmas teóricos, articulando um conjunto de temas e metodologias no percurso da análise da temática - professores.

Ao analisar a pesquisa qualitativa desenvolvida no Centro-Oeste, pautada no MHD, o grupo destaca a seguinte dificuldade: muitos autores assumem a abordagem como equivalente ao método. Assim descrevem nos trabalhos:

[...] Caracterizamos esta investigação como pesquisa qualitativa. Segundo Minayo (1994), a pesquisa qualitativa trata de questões muito particulares [...] (Instituição 5 - Ficha 95).

[...] Para desenvolver este trabalho foi feita a opção pelo método de pesquisa qualitativa porque "a pesquisa qualitativa tem o ambiente natural como sua fonte direta de dados e o pesquisador como seu principal instrumento" onde não ocorre qualquer manipulação intencional do pesquisador com o objeto a ser pesquisado [...] (Instituição 5 - Ficha 96).

[...] A metodologia adotada foi a abordagem qualitativa [...] (Instituição 5 - Ficha 100).

[...] Essa pesquisa foi constituída apoiando-se na teoria qualitativa. Para isso, partimos da apresentação, interpretação e análises dos diversos conhecimen- 
tos que foram sendo construídos com a interação dos diferentes sujeitos da pesquisa [...] (Instituição 3 - Ficha 30).

[...] Por essa razão, ancorada nos escritos desses autores, optei pela metodologia qualitativa interpretativa, com observação da prática pedagógica [...] (Instituição 4 - Ficha 61).

[...] Esta é uma pesquisa descritiva qualitativa, que investiga a possibilidade de evidenciar os saberes de professores e seus modelos pedagógicos, tanto na concepção como na prática docente do Ensino Superior [...] (Instituição 2 - Ficha 18).

O uso impróprio da abordagem e sua identificação com o método ou com a metodologia têm afetado o movimento que possibilitaria ao pesquisador a adequada análise dos dados e consequente elucidação de seu problema de pesquisa. Observa-se também que, na maioria dos estudos, se explicita a abordagem da pesquisa, mas não o referencial teóricometodológico que a sustenta.

Referindo-se ainda à fragilidade da base teórico-metodológica que tem orientado as investigações, identificou-se uma dificuldade recorrente nos estudos da região: a distinção formal que Marx e Engels (1989) fazem do método de pesquisa e método de exposição, aspecto também trabalhado de forma inadequada pelos pesquisadores. Na definição proposta pelos autores, o método de pesquisa trata da apropriação em pormenor da realidade estudada; é a partir dele que se define a análise que evidenciará as relações internas de cada elemento em si: as leis particulares que regem o início, o desenvolvimento e o término de cada objeto investigado ou fenômeno (MARX e ENGELS, 1989). Já o método de exposição ou reconstituição trata da síntese do objeto ou fenômeno estudado; o método de exposição se constitui no desdobramento das antíteses; é na exposição que o objeto desvela-se gradativamente conforme suas peculiaridades.

O método de pesquisa e o método de exposição articulam-s, em sua essencialidade, por meio da lógica dialética que tende a se estender à construção do problema de pesquisa e aos objetivos (outro problema recorrente na totalidade da produção). Portanto, a opção por essa matriz epistêmica também exige coerência com a forma como se configura a escolha do problema e como se elaboram os objetivos.

A partir dessa compreensão, procedeu-se à análise dos objetivos propostos nas pesquisas do Centro-Oeste, buscando-se esclarecer se eles são coerentes com a solicitação metódica no tocante ao movimento dialético. Para tanto se fez necessário empreender uma busca na literatura sobre o tema "formulação de objetivos de pesquisa", visando-se aprofundar o estudo. 
Destaca-se o estudo de Larocca, Rosso e Souza (2005) que empreendeu o exame de vinte e oito obras de Metodologia da Pesquisa, correlacionando o que era descrito na categoria objetivos. Os autores chegaram à conclusão de que os manuais que orientaram (e ainda orientam) as pesquisas revelam pouco acerca dos objetivos; a maioria é vaga ao tratar do assunto, revelando pouco interesse na descrição e importância dos mesmos.

A tipificação dos objetivos de pesquisa utilizados nesse estudo pautou-se, portanto, no estabelecido por Larocca, Rosso e Souza (2005, p.125), quais sejam: objetivos generalistas, objetivos meios e exploratórios, propositivos, descritivos, avaliativos e compreensivos.

Os objetivos generalistas são aqueles em que não é possível estabelecer uma limitação mais ou menos precisa; valem para um elenco enorme de situações e, em muitos casos, apresentam uma redação confusa, como no exemplo abaixo:

O objetivo desse estudo foi obter testemunhos, dando voz a esses professores (as) e, por meio deles, a vida e o pensamento de sujeitos cujo oficio de formar seus contemporâneos tem implicação nos processos de subjetivação também das crianças como um todo, e mais especificamente das crianças negras em formação. Estabelecendo assim uma relação entre a história de vida dos professores e o processo de construção identitária negra, que também é profundamente marcada pela ausência do negro na escola, isto é, do conteúdo intelectual que ela repassa e que está ligado ao lugar que o negro e a discussão sobre a diversidade étnica ocupam na sociedade. Uma ausência contra a qual se posiciona o aporte teórico dessa pesquisa [...] (Instituição 5 - Ficha 105).

Esses objetivos caracterizam-se por serem vagos, abrangentes e por apresentarem ausência de delimitação. São de difícil apreensão, podendo ser identificados através da utilização de expressões verbais como: refletir sobre práticas; despertar, esclarecer práticas; discutir concepções etc..Vejamos os exemplos identificados na produção do Centro-Oeste.

Conhecer em âmbito local as orientações decorrentes do movimento global, com reflexo nas políticas públicas que se tornaram reféns da economia e de organismos externos ao nosso país [...] (Instituição 5 - Ficha 106).

Analisar como tem se desenvolvido o fazer pedagógico no nível primário na visão de professores que fizeram e dos que não fizeram o curso de docência no Timor-Leste [...] (Instituição 6 - Ficha 112).

A sistematização desenvolvida no presente estudo buscou refletir a respeito dessas questões, consideradas numa abordagem da qualidade da educação 
infantil que vai além da busca de seus indicadores [...] (Instituição 6 - Ficha 122).

A presente pesquisa teve por objetivo estudar a formação docente, tal como proposta no Curso Normal Superior Veredas [...] (Instituição 2 - Ficha 20).

Objetivos meios ou exploratórios referem-se a uma etapa que antecede a pesquisa propriamente dita; procuram aproximação com o fenômeno pela busca de informações que poderão auxiliar o pesquisador a conhecer mais a seu respeito e encaminhar ações mais precisas. Esse tipo de objetivo mostra a intenção do pesquisador de atingir respostas para as problematizações e de construir meios para alcançá-las. Portanto, representam estratégias inerentes à metodologia da pesquisa, uma vez que se situam no campo procedimental e não no campo da problematização. São objetivos que se ligam à construção do arcabouço teórico da pesquisa, de levantamentos teóricos e históricos de um dado tema. Muitas vezes, esse procedimento toma o nome conhecido de estado do conhecimento.

É importante considerar que o objetivo exploratório não expressa um resultado de pesquisa propriamente dito, mas representa uma condição para o planejamento da mesma. Esse foi um problema comumente observado nos trabalhos analisados. Na construção de objetivos exploratórios utilizam-se verbos e expressões tais como: fazer um estudo; levantar práticas; realizar o levantamento teórico e histórico; discutir o desenvolvimento das trajetórias profissionais etc.; mas observa-se que esses não dão respostas para as problematizações postas pela pesquisa, visam apenas sustentá-la. Como exemplo, retiramos dos trabalhos analisados:

[...] Conhecer em âmbito local as orientações decorrentes do movimento global, com reflexo nas políticas públicas que se tornaram reféns da economia e de organismos externos ao nosso país [...] (Instituição 5 - Ficha 106).

[...] tomamos como objetivos do presente trabalho: apreender, através de aprofundamento teórico-metodológico, os mecanismos que sustentam ou não as práticas de formação de professores no espaço escolar [...] (Instituição 2 - Ficha 25).

[...] O objetivo geral deste estudo consistiu em levantar as concepções de professores dos cursos de licenciatura, com relação aos saberes teóricos e práticos por eles desenvolvidos, sob a ótica dos Modelos Organizadores de Pensamento [...] (Instituição 2 - Ficha 18).

Os objetivos propositivos também estão presentes nos trabalhos analisados, mas em número reduzido. Esses se preocupam com a apresen- 
tação de sugestões e propostas, elaboração de ações, planos e alternativas, privilegiando a metodologia da resolução de problemas. Exemplos de expressões tomadas dos trabalhos: contribuir para; buscar ou levantar alternativas; propor, definir, subsidiar, construir um plano ou proposta.

[...] propiciar condições para que a autonomia e a apropriação por parte dos profissionais da escola se deem no processo de formação continuada; possibilitar a reconceituação da pesquisa no processo de formação docente [...] (Instituição 2 - Ficha 25).

Os objetivos descritivos aparecem em número mais significativo (veja Tabela 2). Esses se caracterizam pela preocupação predominante de fazer um relato detalhado de ações e procedimentos; ligam-se a exposição de registros, relatos de experiência e narrações. Na sua construção, utilizam-se verbos que transmitem a ideia de exposição minuciosa de passos, caminhos e achados e não comportam discussão ou julgamento do material descrito. É comum a utilização dos verbos: descrever, relatar, traçar, identificar, evidenciar, conhecer, analisar a forma, investigar de que maneira, encontrar, pesquisar sobre; verbos que estão sempre ligados à captação de uma intencionalidade descritiva.

[...] temos como objetivo para esta pesquisa: descrever e analisar as dificuldades e os limites da prática pedagógica de professores de Educação Física das séries finais do ensino fundamental da rede pública municipal [...] (Instituição 2 - Ficha 15).

[...] o objetivo desta pesquisa é descobrir e mostrar que desafios precisam ser vencidos para que os educadores vivam a cultura da educação a distância, em Rede, relacionados a novas lógicas de interação e de comunicação e a princípios éticos, estéticos, políticos e sociais que regem uma nova pedagogia [...] (Instituição 2 - Ficha 27).

[...] Os objetivos da presente pesquisa foram os de conhecer quais as características, funções e modos de funcionamento (individuais e coletivos) presentes no grupo de professores de Arte da Rede Municipal de Ensino [...] (Instituição 3 - Ficha 54).

O estudo mostrou que os diferentes tipos de objetivos diziam respeito tanto aos denominados objetivos gerais quanto específicos. Diferentemente, os objetivos avaliativos estavam presentes apenas entre os objetivos gerais na produção analisada, e em número reduzido (veja Tabela 2). Esses objetivos destacam-se por suas finalidades valorativas, presumindo juízos e apreciações; buscam melhor compreensão e interpretação das motivações e expectativas dos pesquisadores. Pode-se dizer que os objetivos avaliativos 
ligam-se a ações expressas através de verbos muito utilizados como: analisar repercussões; avaliar o alcance; proceder a análises críticas; captar contribuições; avaliar as ações; mapear as práticas pedagógicas; estabelecer relações. Note-se o exemplo:

[...] Neste trabalho buscamos avaliar como o curso de Pedagogia tem contribuído na formação para a docência na educação infantil. Tendo como referência a Pedagogia da Educação Infantil [...] (Instituição 6 - Ficha 122).

Os objetivos compreensivos (que também apareceram em número reduzido na produção considerada, conforme Tabela 2) visam interpretar uma dada realidade ou problema mais amplo; destacam ações destinadas a perceber totalidades de elementos nelas envolvidos ou contidos. Utilizam-se verbos como: entender, compreender, analisar, refletir, investigar, interpretar, discutir. Quando o pesquisador opta por esse tipo de objetivo, implica que está construindo caminhos para maior aprofundamento das análises e, consequentemente, maior relevância da pesquisa. Por exemplo:

[...] tem o objetivo de compreender o processo de construção e/ou reconstrução dos saberes daqueles profissionais que trabalham com jogos nas aulas de matemática de quinta série à oitava série do ensino fundamental, optamos por entrevistar professores que desenvolvem a prática pedagógica com jogos nas aulas de Matemática [...] (Instituição 3 - Ficha 36).

[...] analisar os saberes fazeres musicais de professoras que atuam na educação infantil [...] (Instituição 3 - Ficha 53).

[...] Esta pesquisa objetiva apreender a política de formação de professores do curso Mude-TO, analisando esse curso à luz do modelo de formação de professores orientado pelo BM para a América Latina [...] (Instituição 5 - Ficha 110).

Concorda-se que, na prática acadêmica, os objetivos têm sido definidos como um constituinte formal do texto de pesquisa, delimitador do âmbito da investigação. No nosso entendimento, os objetivos ajudam a delinear o caráter da pesquisa, pois expressa a maturidade epistemológica da trajetória investigativa. Quando estruturados a partir da lógica dialética, também são a expressão de como o pesquisador procura empreender o entendimento do objeto de estudo.

A tabela a seguir explicita a natureza dos objetivos identificados no total da produção analisada (132). 
Tabela 2 - Classificação de todos os objetivos produzidos na produção acadêmica do Centro-Oeste (2006-2007)

\begin{tabular}{|l|c|}
\hline Natureza dos objetivos gerais e específicos & Dissertações e teses \\
\hline Trabalhos que não explicitaram objetivos & 119 \\
\hline Generalistas & 1 \\
\hline Explicativos & 11 \\
\hline Propositivos & 62 \\
\hline Descritivos & 55 \\
\hline Compreensivos & 7 \\
\hline Avaliativos & 190 \\
\hline Total de objetivos identificados na produção & 132 \\
\hline Total de trabalhos analisados & 5 \\
\hline
\end{tabular}

Fonte: Redecentro-Rede de Pesquisadores sobre professores(as) do Centro-Oeste (SOUZA; MAGALHÃES, 2011).

Na sequência, recortam-se, para aprofundamento da análise, os objetivos compreensivos, pois são considerados mais adequados ao método dialético.

Tabela 3 - Classificação dos objetivos produzidos na produção acadêmica do CentroOeste que assumiram o MHD (2006-2007)

\begin{tabular}{|c|c|c|c|c|c|c|c|}
\hline $\begin{array}{c}\text { Instituições } \\
\text { Rede }\end{array}$ & $\begin{array}{c}\text { Instituição } \\
\mathbf{1}\end{array}$ & $\begin{array}{c}\text { Instituição } \\
\mathbf{2}\end{array}$ & $\begin{array}{c}\text { Instituição } \\
\mathbf{3}\end{array}$ & $\begin{array}{c}\text { Instituição } \\
\mathbf{4}\end{array}$ & $\begin{array}{c}\text { Instituição } \\
\mathbf{5}\end{array}$ & $\begin{array}{c}\text { Instituição } \\
\mathbf{6}\end{array}$ & $\begin{array}{c}\text { Instituição } \\
\mathbf{7}\end{array}$ \\
\hline Tipo de Método MHD & $\mathbf{8}$ & $\mathbf{1 3}$ & $\mathbf{8}$ & $\mathbf{2 0}$ & $\mathbf{1 1}$ & $\mathbf{1 5}$ & $\mathbf{7 5}$ \\
\hline TIPOS DE OBJETIVOS & & & & & & & \\
\hline Compreensivos & $\mathbf{1}$ & $\mathbf{2}$ & $\mathbf{3}$ & $\mathbf{4}$ & $\mathbf{4}$ & $\mathbf{5}$ & $\mathbf{1 9}$ \\
\hline Generalistas & 3 & 6 & 5 & 13 & 7 & 3 & $\mathbf{3 7}$ \\
\hline Descritivos & 2 & 5 & 0 & 3 & 2 & 4 & $\mathbf{1 6}$ \\
\hline Avaliativos & 0 & 0 & 0 & 0 & 0 & 2 & $\mathbf{3}$ \\
\hline Propositivos & 0 & 0 & 0 & 0 & 0 & 0 & $\mathbf{0}$ \\
\hline Explicativos & 0 & 0 & 0 & 0 & 0 & 0 & $\mathbf{0}$ \\
\hline TOTAL & & & & & & & \\
\hline
\end{tabular}

Fonte: Redecentro- Rede de Pesquisadores sobre professores(as) do Centro-Oeste (SOUZA; MAGALHÃES, 2011).

Na leitura dos trabalhos, percebe-se que os objetivos são, muitas vezes, escritos sem que estejam ancorados na historicidade, na práxis, na to- 
talidade histórica; portanto, assim definidos, não podem conduzir o trabalho aos fins da dialética, movimento de superação e de transformação; ou seja, o conhecimento a ser produzido não visa o processo prático da ação. No caso dos trabalhos que fazem a opção pelo MHD como método, a pesquisa tem que ser assumida como crítica, como produção de conhecimento que visa à sustentação de uma ação prática, social, política, técnica, transformadora; isso significa que os objetivos propostos não podem ser tomados apenas como aspectos formais, desarticulados do todo.

Tendo como base a proposta de Sánchez Gamboa (2006), ainda é necessário considerar que - para definir objetivos em um trabalho, cuja abordagem está vinculada ao MHD - será necessário compreender tais objetivos articulados às concepções de causalidade, de ciência e critérios de validação (práxis) dos requisitos da prova científica que constituem seus pressupostos epistemológicos.

Os objetivos devem ter coerência também com os pressupostos gnosiológicos da abordagem. Esses se referem aos modos de abstrair, generalizar, conceituar, classificar, formalizar; de conceber o objeto e relacioná-lo com o sujeito, dando ênfase na relação entre eles, na busca da síntese entre o subjetivo e o objetivo. Essa dimensão gnosiológica diferencia esse modo de construção do conhecimento e, em função do movimento dialético que a sustenta, exige a mesma coerência na definição dos objetivos. Desse entendimento, a compreensão do objeto do conhecimento passa a ser um todo articulado com as suas partes constituintes, como produto de um processo de transformação permanente.

Tomando as ideias de Sánchez Gamboa (2006) e de Frigotto (2003; 2008) como base, construímos a tabela de indicadores (Tabela 4) a partir das relações entre os objetivos e pressupostos inerentes ao MHD. A tabela permite visualizar as imprecisões nas definições dos objetivos dos trabalhos analisados. Não se pretende que os objetivos tenham todos descritores derivados do método assumido, mas parece-nos importante que guardem coerência com alguns daqueles (no caso do MHD) que estamos analisando; as categorias - historicidade, contextualidade, totalidade e práxis - parecem indispensáveis de serem consideradas nos objetivos.

Chama a atenção que dentre as pesquisas com objetivos compreensivos desenvolvidos no MHD, quatro não se aproximam de nenhuma dessas categorias. Essa análise possibilita pensar que a definição de objetivos está fragilizada nas pesquisas analisadas, o que nos leva a deduzir que suas conclusões também o são. 
Tabela 4 - Características dos trabalhos que intencionalmente escolheram o MHD como método, e que elaboraram objetivos compreensivos

\begin{tabular}{|l|c|}
\hline Descritores da construção dos objetivos relacionados ao método MHD & $\begin{array}{c}\text { Dissertações e } \\
\text { teses }\end{array}$ \\
\hline $\begin{array}{l}\text { Total de trabalhos que desenvolveram o método MHD. } \\
\text { Os objetivos que: }\end{array}$ & 75 \\
\hline $\begin{array}{l}\text { privilegiem a relação entre o sujeito e o objeto, realizando a síntese entre o subjetivo } \\
\text { e o objetivo }\end{array}$ & 19 \\
\hline $\begin{array}{l}\text { levam em conta os contextos para delimitar o objeto de estudo. No entanto, em } \\
\text { geral, não falam de temporalidade, para construir a historicidade, mas apenas de } \\
\text { espacialidade. }\end{array}$ & \\
\hline $\begin{array}{l}\text { proporcionam o entendimento do contexto como o conjunto de condições } \\
\text { materiais concretas determinantes das características da construção do objeto } \\
\text { (trabalhar com categorias marxistas). }\end{array}$ & 15 \\
\hline $\begin{array}{l}\text { promovem o entendimento do objeto como produto de um processo de } \\
\text { transformação permanente (dialética.) }\end{array}$ & 6 \\
\hline $\begin{array}{l}\text { consideram a realidade histórica na construção do trabalho. A historiografia se torna } \\
\text { indispensável para recuperar a historicidade, e o devir histórico dos fenômenos. }\end{array}$ & 7 \\
\hline consideram a totalidade histórica na conclusão dos estudos. & 3 \\
\hline $\begin{array}{l}\text { promovem o entendimento de que o conhecimento se constitui como um todo } \\
\text { novo que resulta do processo da inter-relação entre um objeto em construção e } \\
\text { um sujeito também em construção; caminhando do todo às partes e, destas ao } \\
\text { todo situado e determinado pelos contextos. }\end{array}$ & 2 \\
\hline $\begin{array}{l}\text { colocam em ênfase nas categorias da temporalidade (tempo) articulando a } \\
\text { historicidade (origem, evolução, transformação) para explicar e compreender o } \\
\text { fenômeno. }\end{array}$ & 0 \\
\hline $\begin{array}{l}\text { são eixo condutor do método de investigação, articulam processos de } \\
\text { transformação dos fenômenos, sua origem e suas fases de evolução. }\end{array}$ & 2 \\
\hline $\begin{array}{l}\text { serem eixo condutor do método MHD, integrando-se ao método de investigação } \\
\text { processual buscando a transformação dos fenômenos, ou seja, sua origem e suas } \\
\text { fases de evolução. Movimento indispensável para recuperar a historicidade do } \\
\text { objeto de estudo, e o devir histórico dos fenômenos, e sua transformação (práxis). }\end{array}$ & 2 \\
\hline
\end{tabular}

Fonte: Redecentro- Rede de Pesquisadores sobre professores(as) do Centro-Oeste (SOUZA;MAGALHÃES, 2011).

Finaliza-se, reafirmando que a definição de objetivos guarda coerência com os pressupostos epistemológicos, gnosiológicos e ontológicos inerentes ao método escolhido para direcionar a pesquisa. Nesse sentido, devem fazer referência a categorias gerais que abrangem, dentre outras, as concepções de homem, de sociedade, de história e de realidade. Categorias que estarão presentes na formulação de objetivos e questões que auxiliem a procurar respostas para os problemas ou fenômenos abordados.

Para os que optam pelo MHD, o delineamento dos objetivos embasa-se na concepção do homem como sujeito ativo transformador, situado em classes sociais opostas de onde uns são explorados e outros exploradores. Ao mesmo tempo, considera-se a sociedade como o lugar onde predomina a contradição, a permanente dinâmica e que é, também, voltada para a transformação, a inovação e a evolução social. Aproxima-se do entendimento 
do objeto, como produto de um processo de transformação permanente de sua totalidade histórica, viabilizando a construção do conhecimento como um todo novo.

Definir objetivos apenas como exigência formal - como tem sido praticado, muitas vezes, na construção dos trabalhos acadêmicos do Centro-Oeste - compromete a qualidade da pesquisa, já que se mostram incoerentes com os pressupostos que devem guiar a realização do trabalho científico e criterioso.

Esse estudo evidenciou a importância de maior aprofundamento e rigor na definição dos objetivos e de sua relação com o método MHD na produção acadêmica, o que sugere um aprofundamento teórico-metodológico dos pesquisadores e indica a pertinência da sua continuidade.

IMPLICATIONS OF THE METHODOLOGICAL OPTION FOR HISTORICAL AND DIALECTICAL MATERIALISM IN THE SCIENTIFIC PRODUCTION OF THE BRASILIAN MIDWEST

ABSTRACT: This article presents the results of an analysis of the scientific production on teachers, from 2006 to 2007, in Postgraduate Programs in Education in the Midwest. Based on Historical and Dialectical Materialism (HDM), it was produced by REDECENTRO - a Research Network on teachers in the Midwest. It sets out to analyze what is produced based on the option for HDM as a method, as well as its relations with the qualitative approach, the objectives and the conclusions reached. A lack of clarity between the significance of method and the approach of the study, as well as theoretical and methodological dispersion were identified. As for the goals related to HDM, there is need to see to it that the objectives are more than mere compliance with a formality, and that there be comprehensive goals, related to the same epistemological, ontological, and gnosiological presuppositions reclaimed in the conclusions of the studies.

KEYWORDS: Educational research. Teacher formation. Method.

IMPLICACIONES DE LA OPCIÓN METODOLÓGICA POREL MATERIALISMO HISTÓRICODIALÉCTICO EN LA PRODUCCIÓN ACADÉMICA DEL CENTRO OESTE DEL BRASIL

RESUMEN: Este artículo presenta los resultados del análisis de la producción académica enfocada en los profesores realizada en el período de 2006 a 2007 en los programas de posgrado en educación del Centro Oeste Brasileño. Regida por el materialismo histórico-dialéctico (MHD), esta investigación fue desarrollada por la REDECENTRO - Red de investigación sobre docentes en el Centro Oeste. El presente trabajo tiene como objetivo analizar las investigaciones cuyo desarrollo fue regido por la opción del MHD como método, así como sus relaciones con el abordaje cualitativo, los objetivos 
y las conclusiones construidas. Se identificó la falta de claridad entre el significado del método y el abordaje del trabajo, bien como la dispersión teórica y metodológica. Con respecto a los objetivos relacionados al MHD, se destaca la necesidad de superar la consideración de los objetivos como un simple cumplimiento de formalidad, y que estos sean construidos de forma compreensiva, relacionados a las mismas presuposiciones epistemológicas, ontológicas, gnosiológicas y recuperados en las conclusiones de los estudios.

PalABRAS ClAVES: Investigación educacional. Formación de profesores. Método.

\section{NOTAS}

1. Pesquisa financiada pelo Conselho Nacional de Desenvolvimento Científico e Tecnológico - CNPq.

2. "Hoje a CAPES já não pode ser considerada como política de um governo, mas uma política de estado. E tal é o seu poder que não se pensa em extinção. Fala-se muito na necessidade de mudanças, mas no dia a dia das universidades, preponderantemente, trabalha-se para uma melhor classificação, seja das menores unidades, dos programas, seja das instituições. A impressão é que a CAPES já está incorporada e é operacional, evidenciada por alguns como um mal necessário" (BIANCHETTI, 2011, p. 443-444).

3. Antes do período de 1999, há pesquisas que analisaram a produção (ANDRÉ, 2007; BRZEZINSKI, 2002).

4. É preciso observar que $20 \%$ da produção analisada correspondem a um total de 72 trabalhos; entretanto após segunda leitura dos mesmos, chegou-se à conclusão que seis delas deveriam ser retiradas da análise por não corresponderem aos critérios estipulados.

\section{REFERÊNCIAS}

ANDRÉ, M. A. Questões sobre os fins e sobre os métodos de pesquisa em Educação. Revista Eletrônica de Educação. São Carlos. São Paulo: UFSCar, v.1, n. 1, p. 119-131, set. 2007.

ANDRÉ, M. A. Pesquisas sobre formação de professores: tensões e perspectivas do campo. In: FONTOURA H. A. da; SILVA, M. (Org.). Formação de professores, culturas: desafios à pós-graduação em educação em suas múltiplas dimensões. Rio de Janeiro: ANPEd Nacional, 2011.

BELLO, Â. A. Introdução à fenomenologia. Bauru, SP: Edusc, 2006.

BIANCHETTI, L. Condições de trabalho e repercussões pessoais e profissionais dos envolvidos com a pós-graduação stricto sensu: balanço e perspectivas. Linhas Críticas, Brasília, DF, v. 17, n. 34, p. 439-460, set./dez. 2011. 
BICUDO, M. A. V. Sobre a fenomenologia. In: BICUDO, M. A.V.; ESPOSITO, V. H. C. Pesquisa qualitativa em educação. Piracicaba: Unimep, 1994. p.15-22.

BRZEZINSKI, I. Profissão professor: identidade e profissionalização docente. Brasília: Plano, 2002

CUNHA, L. A. Os (des)caminhos da pesquisa na pós-graduação. In: SEMINÁRIO SOBRE A PRODUÇÃO CIENTÍFICA NOS PROGRAMAS DE PÓS-GRADUAÇÃO EM EDUCAÇÃO, Brasília, CAPES/MEC, 1979.

FRIGOTO, G. Educação e crise do capitalismo real. São Paulo: Cortez, 2003.

FRIGOTO, G. Educação e trabalho: bases para debater a Educação Profissional Emancipadora. Perspectiva, Florianópolis, v. 19, n. 1, p. 71-87, jan./jun. 2008.

GATTI, B. A. Pós-graduação e pesquisa em educação no Brasil: 1978-1981. Cadernos de Pesquisa, São Paulo, n. 44, p. 3-17, fev. 1983.

GATTI, B. A. Pesquisa em educação: um tema em debate. Cadernos de Pesquisa, São Paulo, n. 80, p. 106-111, fev. 1992.

GATTI, B. A. Implicações e perspectivas da pesquisa educacional no Brasil contemporâneo. Cadernos de Pesquisa, São Paulo, n. 113, p. 65-81, jul. 2001.

GATTI, B. A. A construção da pesquisa em educação no Brasil. Brasília: Plano, 2002.

GOUVEIA, A. J. A pesquisa educacional no Brasil. Cadernos de Pesquisa, São Paulo, n. 1, p. 1-48, jul. 1971.

GOUVEIA, A. J. A pesquisa sobre educação no Brasil: de 1970 para cá. Cadernos de Pesquisa, São Paulo, n. 19, p. 75-80, dez. 1976.

KUENZER, A. Z.; MORAES, M. C. M. de. Temas e tramas na pós-graduação em educação. Campinas: Educ. Soc., v. 26, n. 93, p. 1341-1362, dez. 2005.

LAROCCA, P; ROSSO, A. J.; SOUZA , P. de. A formulação de objetivos de pesquisa na pós-graduação em Educação: uma discussão necessária. In: Revista Brasileira de Pós-Graduação, v. 2, n. 3, p. 118-133, mar. 2005.

LIMOEIRO, M. C. O mito do método. Rio de Janeiro: Boletim carioca de geografia, ano XXV, 1976.

LIMOEIRO, M. C. Ideologia do desenvolvimento. Brasil: JK-JQ. Rio de Janeiro: Paz e Terra, 2. ed., 1978.

LUNA, S. V. de. O falso conflito entre tendências metodológicas. Cadernos de Pesquisa. São Paulo, n. 66, p. 70-74, ago. 1988.

MAGALHÃES, S. M. O.; SOUZA, R. C. C. R. de.; Veredas metodológicas da pesquisa em educação da região Centro-Oeste/Brasil. Educação \& Realidade - ISSN 0100-3143 (impresso) e 2175-6236 (online) Educ. Real., Porto Alegre, v. 37, n. 1, jan./abr. 2012.

MARX, K. ; ENGELS, F. A ideologia alemã. 7. ed. São Paulo: Hucitec, 1989. 
MELLO, G. N. de. Pesquisa em educação: questões teóricas e questões de método. Cadernos de Pesquisa, São Paulo, n. 40, p. 6-10, fev. 1982.

MELLO, G. N. de. A pesquisa educacional no Brasil. Cadernos de Pesquisa, São Paulo, n. 46, p. 67-82, ago. 1983.

MELLO, G. N. de. Pesquisa educacional, políticas governamentais e o ensino de $1^{\circ} \mathrm{grau}$. Cadernos de Pesquisa, São Paulo, n. 53, p. 25-31, maio 1985.

MINAYO, M. C. de S. Ciência, técnica e arte: o desafio da pesquisa social. In: MINAYO, M. C. de S.(Org.). Pesquisa Social: teoria, método e criatividade. Petrópolis: Vozes, 1994.

SÁNCHEZ GAMBOA, S. Pesquisa em educação: métodos e epistemologias. Chapecó: Argos, 2006.

SÁNCHEZ GAMBOA, S. A dialética na pesquisa em educação: elementos de contexto. In:SÁNCHEZ GAMBOA, S. Pesquisa em Educação: métodos e epistemologias. Campinas: Papirus, 2007.

SOUZA, R. C. C. R. de; MAGALHÃES, S. M. O. (Org.). Método e metodologia na pesquisa sobre professores(as). In: Pesquisa sobre professores(as), métodos, tipos de pesquisas, temas, ideário pedagógico e referenciais. Goiânia: Editora Puc-Goiás, 2011.

RUTH CATARINA CERQUEIRA R. DE SOUZA é doutora em Psicologia pela Université Paul Valéry (França); professora do curso de Pedagogia e da Pós-Graduação em Educação da Universidade Federal de Goiás/UFG; vinculada à Linha de pesquisa: formação, profissionalização docente e práticas educativas; coordenadora da REDECENTRO e membro do Observatório Internacional da Profissão Docente - OBIPD. E-mail: ruthcatarina@smail.com

SOLANGE MARTINS OLIVEIRA MAGALHÃES é doutora em Educação pela Universidade Federal de Goiás/UFG; professora no curso de Pedagosia e Pós-Graduação em Educação da FE/UFG; vinculada à Linha de pesquisa: formação, profissionalização docente e práticas educativas; coordenadora/UFG da REDECENTRO; membro do Observatório Internacional da Profissão Docente - OBIPD.

E-mail: solufg@hotmail.com 